\title{
FUNDAMENTOS FILOSÓFICOS DE LA VIDA SOCIAL Y DE LA CONVERSACIÓN EN EL SIGLO DE ORO
}

\author{
Christoph Strosetzki
}

De un tiempo a esta parte, la Pragmática lingüística ha venido poniendo de relieve que el habla es una acción. Sin embargo, la acción es el campo de la ética. Así pues, ¿qué relación se establece entre las normas de la ética y las reglas de la conversación? La pregunta puede responderse a primera vista con bastante facilidad si uno se pregunta, por ejemplo, por la permisividad frente a la mentira y el engaño. La cuestión se vuelve más compleja si se compara el sistema de la ética con el sistema de las reglas de conversación, algo que emprenderemos en la primera parte de este trabajo. Pasaremos después a relacionar las formas de convivencia regulada en la vida social y la conversación con las de la política y el Estado. Se plantea aquí la cuestión de hasta qué punto cabe establecer una analogía entre la sociedad que se reúne en conversación sociable y la sociedad del Estado, de forma que puedan extraerse paralelismos entre la teoría política y la teoría de la vida social. En vista de la notable presencia de Aristóteles y santo Tomás de Aquino en la escolástica tardía del Siglo de Oro, partiremos de la ética y la política aristotélicas.

En el capítulo dedicado a las virtudes éticas de la Ética nicomáquea, Aristóteles explica las virtudes de las relaciones sociales, enmarcadas en una enumeración en la que les anteceden las virtudes de la valentía, la moderación, la liberalidad y la ambición y en la que les siguen las virtudes del pudor y de la justicia. "A los que divierten a los otros

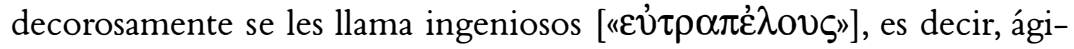
les de mente»'. Así, la virtud de la agudeza en la conversación se pue-

' Aristóteles, Ética nicomáquea, p. 234. 
de denominar, apoyándonos en Aristóteles, eutrapelia. Este diferencia a los complacientes de los pendencieros. Los primeros todo lo alaban, nunca expresan una opinión contraria y no exigen de su interlocutor nada molesto, mientras que a los segundos no les importa parecer molestos por sus continuas protestas. En este caso, como en todo el resto de virtudes, aconseja Aristóteles un término medio en el que uno acepte de los demás lo debido como es debido y rechace lo demás de manera análoga. Parece obvio que la rectitud que aconseja está vinculada a la justicia. Al fin y al cabo, define Aristóteles que el transgresor de la ley es injusto y el que se ajusta a ellas, justo. Dado que las leyes incumben a todos los ámbitos de la vida, una acción será justa si "produce o preserva la felicidad o sus elementos para la comunidad política» ${ }^{2}$. Si la justicia logra aquello que es útil para los demás, se aplica entonces más a los demás que cualquier otra cualidad del carácter. Esto se muestra de forma muy significativa en el caso del ejercicio de poder. En este punto es comparable a las virtudes de las relaciones sociales, que, por su parte, consisten en el cumplimiento de reglas y leyes y persiguen el fin de la felicidad y el placer.

Frente al jactancioso, que se presenta más grande de lo que en realidad es, y al irónico, que minimiza sus méritos, Aristóteles recomienda la sinceridad como término medio. También en los momentos de ocio ha de mantenerse el término medio para, por una parte, no sobrepasar los límites de lo cómico y no hacer el ridículo cual bufón o, por otro lado, no parecer un patán que muestra su aspereza con cada broma. "El que es gracioso y libre se comportará como si él mismo fuera su propia ley. Tal es el término medio ya sea llamado hombre de tacto o ingenioso" ${ }^{3}$. Este término medio, consistente en una correcta evaluación de la conversación por parte del interlocutor, se corresponde con lo que Aristóteles llama en su Retórica $\pi \rho \varepsilon \dot{\pi} \sigma o v$, aptum en latín. Lo mismo se muestra también cuando aconseja conceder a cada uno lo que le corresponda, ya sean amigos íntimos o extraños, hombres de posición elevada o el vulgo. En sus explicaciones sobre el placer y la felicidad como fin de las virtudes, Aristóteles argumenta de forma similar cuando le parece importante para la virtud moral «disfrutar con lo que se debe y odiar lo que se debe» ${ }^{4}$. El término me-

${ }^{2}$ Aristóteles, Ética nicomáquea, p. 240.

${ }^{3}$ Aristóteles, Ética nicomáquea, p. 235.

${ }^{4}$ Aristóteles, Ética nicomáquea, p. 378. 
dio y el $\pi \rho \dot{\varepsilon} \pi o v$ son igualmente modelos de conducta para las virtudes y para la aplicación de reglas de conversación, pues ambos son provechosos para el placer y la felicidad.

Aristóteles introduce el "término medio" también en la amistad, si bien en esta se entremezclan igualmente los sentimientos. Aconseja transmitir alegría, pero previene también de aquellos que solo pretenden ser populares y de los aduladores, quienes solamente buscan dinero y beneficios. Las relaciones de amistad se convierten en paradigma de una vida social exitosa y de un Estado exitoso: "pues los que conviven se complacen recíprocamente y se procuran beneficios ${ }^{5}$. Uno no se hace amigo de los hombres de carácter agrio ni de los molestos, pues la Naturaleza evita ante todo lo molesto y aspira a lo agradable. "Pero es imposible estar unos con otros, si no son agradables entre sí, ni se complacen en las mismas cosas» ${ }^{6}$. Aristóteles añade además que los poderosos tienen grupos de amigos diferenciados: en unos, hombres hábiles para ejecutar las órdenes, buscan lo útil, mientras que en los otros, los graciosos, buscan lo agradable ${ }^{7}$. Si estos últimos fomentan un trato social divertido y alegre, encarnan el interlocutor ideal, y al mismo tiempo conforman el grupo central del que pueden derivarse otros grupos de diferentes dimensiones.

Puesto que es bastante común denominar amigos a compañeros de navegación o de campaña, se muestra así que hay amistades de intensidad variada. Aristóteles formula del siguiente modo las reglas propias y características de cada grupo:

Por otra parte, es natural que la justicia crezca juntamente con la amistad, puesto que las dos residen en las mismas personas y tienen la misma extensión.

Ahora bien, todas las comunidades parecen parte de la comunidad política, pues los hombres se asocian con vistas a algo conveniente y para procurarse alguna de las cosas necesarias para la vida. La comunidad política parece haber surgido y perdurar por causa de la conveniencia; a esto tienden también los legisladores, que dicen que es justo lo que conviene a la comunidad. Todas las demás comunidades persiguen el interés particular ${ }^{8}$.

\footnotetext{
${ }^{5}$ Aristóteles, Ética nicomáquea, p. 331.

'Aristóteles, Ética nicomáquea, p. 332.

${ }^{7}$ Aristóteles, Ética nicomáquea, p. 334.

${ }^{8}$ Aristóteles, Ética nicomáquea, pp. 339-340.
} 
Las comunidades de las más variadas formas, por ejemplo, la comunidad que se reúne para celebrar un banquete, constituyen formas especiales de amistad. Así, los miembros de la polis se diferencian de un grupo de amigos solamente por la cantidad. Ante la cuestión de si existe una medida tanto para la cantidad de amigos como para el número de miembros de una polis, declara Aristóteles: «Porque ni diez hombres llegan a constituir una ciudad, ni persiste la ciudad si la aumentamos en cien mil»" Así pues, sí hay una diferencia cuantitativa, mas no cualitativa, entre la polis y un grupo de amigos reunidos en conversación.

La cercanía entre ética y política surge del hecho de que la felicidad es el fin perseguido tanto por el individuo como por la comunidad, y todas las leyes y las artes son simplemente medios para alcanzar el fin de la felicidad. Ante la cuestión acerca de la felicidad, Aristóteles se encuentra en su Ética nicomáquea en el ámbito de la ciencia política. La felicidad es para él sinónimo de vivir bien y obrar bien. En la felicidad, diferencia tres géneros de vida: el más bajo lo constituye el disfrute animal, le sigue el honor al servicio del Estado y, por último, se encuentra la felicidad perfecta, que es la vida contemplativa, considerada la felicidad más placentera ${ }^{10}$. Mientras que en otros casos se eligen ciertos fines por mor de otros fines, la felicidad es el objetivo final, pues es un fin en sí mismo, no como el dinero, por ejemplo, que es un objetivo que elegimos por otra razón. Para Aristóteles, la felicidad es actividad, y aquel que pasa su vida durmiendo carece de ella. La vida es, pues, estar activo en el ámbito social y con las habilidades que a uno más le agradan. Además, dado que la vida activa es más fácil si se está en compañía de otros, la felicidad requiere de cooperación: «Pues bien, la vida de un solitario es dificil, pues no le es fácil estar continuamente activo consigo mismo, pero en compañía de otros y en relación con otros es mucho más fácil» ${ }^{11}$. Aristóteles introduce también otro argumento:

Y si el hombre virtuoso está dispuesto para el amigo como para consigo mismo (porque el amigo es otro yo); entonces así como la propia

\footnotetext{
${ }^{9}$ Aristóteles, Ética nicomáquea, pp. 373-374.

${ }^{10}$ Aristóteles, Ética nicomáquea, pp. 134, 395.

"Aristóteles, Ética nicomáquea, p. 371.
} 
existencia es apetecible para cada uno, así lo será también la existencia del amigo, o poco más o menos. [...] Por tanto, si para el hombre dichoso la existencia, que por naturaleza es buena y agradable, es deseable por sí misma, y la existencia del amigo es para él algo semejante, entonces el amigo será también una de las cosas deseables ${ }^{12}$.

Las amistades se fundan sobre la base de la igualdad: "en efecto, los amigos reciben y desean lo mismo recíprocamente, o se cambian una cosa por otra» ${ }^{13}$.

Se muestra así que, en opinión de Aristóteles, la habilidad que hace funcionar las relaciones sociales y la conversación, la eutrapelia, es una virtud y, al igual que otras virtudes, ha de seguir el criterio del término medio. Así como la virtud de la valentía constituye el término medio entre los vicios de la cobardía y la temeridad, también es aconsejable un término medio en la conversación, que se situaría entre los complacientes y los pendencieros, entre el bufón y el áspero. En Aristóteles, las reglas de conversación están, pues, basadas en la ética. La virtud de las relaciones sociales, como la virtud de la justicia, se aplica a los demás, se refiere a aquellos a quienes hay que tratar como se debe. La capacidad de juicio necesaria para ello la denomina Aristóteles justicia en la ética, y $\pi \rho \dot{z} \pi 0 v$ en la retórica, con lo que la teoría de la conversación se muestra de nuevo como parte de la ética.

Para Aristóteles, el paradigma de la relación social exitosa es la amistad que busca interlocutores agradables, pues esta evita lo molesto tanto como aspira al placer y a la felicidad. El placer y la felicidad comunes, entendiéndose por ello también el bien común aristotélico, es el fin de las leyes y reglas tanto del círculo de amigos como de la polis. Así, la conversación agradable en el círculo de amigos se convierte en el paradigma del Estado exitoso. La teoría de la conversación se convierte en un modelo para la política, pues ambos tienen, como también sucede con la ética, el mismo fin: el placer y la felicidad. A ello se añade que Aristóteles define la vida como actividad que da mejor resultado cuando se lleva a cabo junto con otros. De esto resultan unos fundamentos antropológicos de las relaciones sociales y de la conversación en la ética y en la política, fundamentos cuyo objetivo es la felicidad.

${ }^{12}$ Aristóteles, Ética nicomáquea, pp. 372-373.

${ }_{13}^{13}$ Aristóteles, Ética nicomáquea, p. 334. 
El sistema aristotélico debe la congruencia de la teoría de las relaciones sociales, la ética y la política al hecho de que el fin comúnmente perseguido es el placer y la felicidad. La armonía del conjunto quedaría destruida si los fines del individuo se diferenciaran de los de la sociedad. Esto es lo que sucedía en el primer cristianismo, donde se consideraba fin último la salvación eterna de cada individuo en el más allá y que con san Agustín separó la civitas dei y la civitas terrena. En la Alta Edad Media, santo Tomás de Aquino recurrió de nuevo a Aristóteles y emprendió el intento de enlazar el modelo aristotélico con un trasfondo cristiano. Más tarde, Maquiavelo separó la teoría de la política exitosa de la ética al diferenciar los fines del gobernante de los de sus súbditos. Así pues, en el contexto de la teoría de las relaciones sociales de la temprana Edad Moderna se presentan cuatro modelos: el aristotélico, el del primer cristianismo, el acuñado por santo Tomás y el influido por Maquiavelo.

En la fase del primer cristianismo, la destreza en la conversación cae en descrédito y la eutrapelia, tan aplaudida por Aristóteles, se utiliza como insulto si uno quiere desprestigiar a otro tachándole de farsante chismoso ${ }^{14}$. Con san Ambrosio se ve de forma más clara la relativización de este mundo mediante el más allá:

Incluso en las charlas han de evitarse [las bromas] para que no desprendan de su dignidad a otros temas de conversación más serios. ¡Ay de vosotros, los que ahora reís, porque lloraréis!, advertía el Señor. [...] Y digo que no sólo se deberían evitar las bromas ligeras, sino todo tipo de bromas $[\ldots]^{15}$.

La mala conciencia es lo que lleva, según san Juan Crisóstomo (349-407), a que el discurso despreocupado parezca inaceptable: «No es este mundo un teatro de risa, ni nos hemos juntado en él para soltar la carcajada, sino para gemir y ganar con nuestros gemidos la herencia del reino de los cielos. [...] Porque no es Dios quien da las diversiones, sino el diablo» ${ }^{16}$. Lo que san Ambrosio y san Juan

${ }^{14}$ Rahner, 1954, p. 348.

15 Trad. prop. de Ambrosio de Milán, De officiis ministrorum, pp. 872-873 ("Cavenda enim etiam in fabulis, ne inflectant gravitatem severioris propositi. Vae vobis, qui ridetis, quia flebitis (Lwc. VI, 21)! ait Dominus [...]. Non solum profusos, sed omnes etiam jocos declinandos arbitror [...]").

${ }^{16}$ Juan Crisóstomo, Homilías sobre el Evangelio de San Mateo, vol. I, pp. 119-120. Para la versión latina ver: Juan Crisóstomo, «Homiliae in Matthaeum», p. 70 ("Hoc 
Crisóstomo advierten a todos, lo exigen de manera aún más severa las reglas de san Benito del año 530 para los monjes:

El grado nono de humildad es si el monje reprime su lengua para hablar, y guardando silencio, no habla hasta ser preguntado, enseñándonos la Escritura que en el mucho hablar no se evita el pecado, y que el hombre hablador no prospera en la tierra.

El décimo grado de humildad consiste en no ser fácil y pronto en reír, porque escrito está: El necio en la risa levanta su voz.

El undécimo grado de humildad consiste en que cuando el monje hable, lo haga suavemente y sin risa, humildemente y con gravedad, diciendo pocas palabras y razonables y sin levantar la voz, como está escrito: El sabio se da a conocer por las pocas palabras ${ }^{17}$.

Se demuestra así que en esta temprana etapa del cristianismo no solo la carcajada, sino incluso la conversación despreocupada y juguetona, parecían propias del diablo, pues desviaban a los hombres de la humildad y hacían perder de vista lo pecaminoso. La dignidad de la comunidad de monjes consiste, también en la conversación, en el ascetismo.

Santo Tomás cita a san Ambrosio y a san Juan Crisóstomo y rebate la postura negativa de estos al definir la conversación como juego y recreo, de los cuales el alma tiene tanta necesidad como el cuerpo la tiene de la tranquilidad, pues, dada la limitación de sus fuerzas, no puede trabajar de forma ininterrumpida. Santo Tomás lo ejemplifica con un arco, que se rompería si tuviera que lanzar flechas sin interrupción. Santo Tomás cita literalmente a Aristóteles:

quippe theatrum non risum admittit: neque ideo convenimus, ut cachinnos effundamus, sed ut gemamus, [...]. Non enim Deus id dat ut ludamus, sed diabolus»).

${ }^{17}$ En Colombás, 1954, pp. 387-389. («Nonus humilitatis gradus est, si linguam ad loquendum prohibeat monachus et, taciturnitatem habens, usque ad interrogationem non loquatur, monstrante scriptura quia: In multiloquio non effugitur peccatum. Et quia:Vir linguosus non dirigitur super terram. Decimus humilitatis gradus est, si non sit facilis ac promptus in risu, quia scriptum est: Stultus in risu exaltat vocem suam. Undecimus humilitatis gradus est, si, cum loquitur monachus, leniter et sine risu, humiliter cum gravitate vel pauca verba et rationabilia loquatur, et non sit clamosus in voce, sicut scriptum est: Sapiens verbis innotescit paucis"). 
Por consiguiente, puede existir una virtud que se ocupe de los juegos, virtud a la que el Filósofo llama eutrapelia. Al que la práctica lo llamamos eutrapélico, derivado de buen cambio, porque convierte dichos o hechos en motivo de recreo. Y en cuanto que esta virtud hace que el hombre se refrene de la falta de moderación en el juego, pertenece a la modestia ${ }^{18}$.

Santo Tomás recurre al libro cuarto de la Ética nicomáquea de Aristóteles cuando trata del comportamiento exterior, que ha de ser controlado, pues uno será juzgado después por otros:

En efecto, en cuanto que nos ordenamos hacia otros por medio de los actos exteriores, la moderación de los movimientos exteriores pasa a ser objeto de la amistad o afabilidad, que se ocupa de los gozos y tristezas de las palabras o de los hechos en orden a los otros con los que el hombre convive. Pero en cuanto que estos movimientos exteriores son signos de la disposición interior, su moderación pertenece a la virtud de la verdad, por lo cual nos mostramos, en las palabras y en las acciones, como somos interiormente ${ }^{19}$.

De la necesidad de tener un círculo de amigos, subrayada por Aristóteles, santo Tomás hace una virtud, la amistad («amicitia»), que además vincula a la afabilidad («affabilitas»). Una virtud, según santo Tomás, siempre está dirigida al bien y es requisito para el orden:

$\mathrm{Y}$ es necesario que exista un orden convincente entre el hombre y sus semejantes en la vida ordinaria, tanto en sus palabras como en sus obras; es decir, que uno se comporte con los otros del modo debido. Es preci-

${ }^{18}$ Tomás de Aquino, Suma de Teología, p. 561. Para la versión latina ver: Tomás de Aquino, Summa theologica, 1993, pp. 338-339 ("Et ideo circa ludos potest esse aliqua virtus, quam Philosophus eutrapeliam nominat. Et dicitur aliquis eutrapelus a bona versione, quia scilicet bene convertit aliqua dicta vel facta in solatium. Et inquantum per hanc virtutem homo refrenatur $a b$ immoderantia ludorum, sub modestia continetur»).

${ }^{19}$ Tomás de Aquino, Suma de Teología, p. 559. Para la versión latina ver: Tomás de Aquino, Summa theologica, 1993, p. 343 («Inquantum enim per exteriores motus ordinamur ad alios, pertinet exteriorum motuum moderatio ad amicitiam vel affabilitatem, quae attenditur circa delectationes et tristitias quae sunt in verbis et factis in ordine ad alios quibus homo convivit. Inquantum vero exteriores motus sunt signa interioris dispositionis, pertinet eorum moderatio ad virtutem veritatis, secundum quam aliquis talem se exhibet in verbis et factis qualis est interius"). 
so, pues, una virtud que observe este orden convenientemente. $Y$ a esta virtud la llamamos amistad o afabilidad ["Et haec vocatur amicitia sive affabilitas»] ${ }^{20}$.

De este modo, santo Tomás rehabilita el principio aristotélico del placer y la felicidad. Para él, todo aquello que contradiga la razón humana es pecaminoso, y va contra la razón "el mostrarse oneroso para con los otros, es decir, el no proporcionarles nada agradable e impedir los deleites de los otros ${ }^{21}$. Por supuesto, tanto los deleites como el juego han de mantenerse siempre en una justa medida y en el término medio, con lo cual se rehabilita la virtud de la eutrapelia en la conversación como recreo y juego. Santo Tomás lo formula de la siguiente manera:

Y así muestra Aristóteles cuál es el término medio en el trato con el juego. Afirma que aquellos hombres que mantienen la justa medida en el juego, son llamados "eutrapeli», lo cual significa hombres ágiles, porque convierten de modo adecuado todo lo que se dice o se hace en risa ${ }^{22}$.

Aunque la principal intención de la amicitia y la affabilitas tomasianas es agradar a aquellos con quienes se convive, estas no han de va-cilar en entristecer cuando sea necesario para así alcanzar un bien o evitar un mal. Si no es así, los elogios se convierten en pecados ${ }^{23}$. La valoración de la gravedad de los pecados depende de la intención. Si uno solo ha adulado para agradar a otros y no ha contravenido con

${ }^{20}$ Tomás de Aquino, Sumna de Teología, p. 265.Versión latina en Tomás de Aquino, Summa theologica, 1943, p. 188 ("Oportet autem hominem convenienter ad alios homines ordinari in communi conversatione, tam in factis quam in dictis, ut scilicet ad unumquemque se habeat secundum quod decet. Et ideo oportet esse quandam specialem virtutem quae hanc convenientiam ordinis observet. Et haec vocatur amicitia sive affabilitas»).

${ }^{21}$ Tomás de Aquino, Suma de Teología, p. 563.Versión latina en Tomás de Aquino, Summa theologica, 1993, p. 346 («Est autem contra rationem ut aliquis se aliis onerosum exhibeat, puta dum nihil delectabile exhibet, et etiam delectationes aliorum impedit»).

22 Trad. prop., versión latina en Tomás de Aquino, Ethicorum Aristotelis ad Nicomachum, p. 236 ("Ostendit quid sit medium in ludo. Et dicit, quod illi qui moderate se habent in ludis vocantur eutrapeli, quasi bene vertentes, quia scilicet ea quae dicuntur ac fiunt convenienter in risum convertunt»).

${ }^{23}$ Tomás de Aquino, Suma de Teología, pp. 268-269. 
ello el preceptivo amor al prójimo, entonces no se puede hablar de un pecado mortal, sino solo venial ${ }^{24}$.

Al igual que sucedía con Aristóteles, en santo Tomás la convivencia también es una necesidad para que los unos apoyen a los otros: «La prueba más evidente de ello es que solamente el hombre posee la capacidad de utilizar la lengua, con lo cual puede comunicar al resto todos sus conceptos ${ }^{25}$. Es natural al hombre vivir en compañía de otros, pues no podría afrontar él solo las necesidades de la vida ${ }^{26}$. En este punto, santo Tomás sigue de forma bastante exacta las normas de Aristóteles.

En principio, sucede lo mismo con la ética, si bien entra en juego el concepto cristiano del pecado. Así pues, el vivir bien, o lo que es lo mismo, el placer y la felicidad, queda reemplazado como fin último por "la vida bienaventurada, que esperamos en el cielo» ${ }^{27}$, lo que en santo Tomás pasa a ser el nuevo fin último. La verdad o veracidad es la actitud de aquellos que dicen la verdad y, en ella, lo verdadero es la adecuación del entendimiento o del signo con la cosa entendida o significada. La veracidad es una virtud, pues está encaminada al bien y dirigida por la voluntad. Como virtud moral es un hábito que se encuentra entre dos extremos, esto es, el término medio entre el que exagera y el que queda corto al hablar sobre sí mismo: «El exceso se da en quien dice lo que hay, pero a destiempo; y el defecto en quien lo oculta cuando conviene decirlo" ${ }^{28}$. En la medida en que la verdad esté dirigida ad alterum le parecerá a santo Tomás comparable a la justicia ${ }^{29}$. La mentira es para él lo que se dice contradiciendo las

${ }^{2+}$ Tomás de Aquino, Suma de Teología, pp. 269-270.

${ }^{25}$ Trad. prop., versión latina en Tomás de Aquino, De regimine principum, pp. 67 («Hoc etiam evidentissime declaratur per hoc, quod est proprium hominis locutione uti, per quam unus homo aliis suum conceptum totaliter potest exprimere»).

${ }^{26}$ Tomás de Aquino, De regimine principum, p. 9.

${ }^{27}$ Versión latina en Tomás de Aquino, De regimine principumn, p. 57 («Sicut autem ad vitam, quam in caelo speramus beatam, ordinatur sicut ad finem vita qua hic homines bene vivunt»).

${ }^{28}$ Tomás de Aquino, Sumıa de Teología, p. 241.Versión latina en Tomás de Aquino, Summa theologica, 1943, p. 124 ("Superfluum autem convenit illi qui importune ea quae sua sunt manifestat, defectus autem competit illi qui occultat, quando manifestare oportet»).

${ }^{29}$ Tomás de Aquino, Suma de Teología, p. 241. Aquí se dice: «La virtud de la verdad coincide con la justicia en dos notas: una, en lo de referirse a otro.Y, en efec- 
opiniones propias y cabe diferenciar tres aspectos: en primer lugar, la falsedad de lo que se dice; en segundo lugar, la intención de decir algo falso; y, en tercer lugar, la intención de engañar. No obstante, no toda mentira es pecaminosa en el mismo grado. Santo Tomás recurre a Pedro Lombardo y diferencia tres tipos teniendo en cuenta el efecto de dichas mentiras: primero, las mentiras oficiosas, en las que se pretende un bien útil; segundo, las jocosas, para conseguir un bien de deleite; $y$, por último, las perniciosas, que tienen la intención de perjudicar a otro. Si el fin que se desea alcanzar en el primer y en el segundo caso no daña al prójimo, no se trata entonces de pecados mortales ${ }^{30}$. En definitiva, puede decirse que santo Tomás se distanció de san Ambrosio y del primer cristianismo y se acercó en gran medida a Aristóteles, si bien se desvió de este al fijar como norma un nuevo fin último y determinar la igualdad de vida social, ética y política. De este modo, entre las tareas del rey estaría "procurar la buena vida de sus súbditos por los medios que más convengan, para que alcancen la celestial bienaventuranza $[\ldots]{ }^{31}$.

Esta es una preocupación que ya no tiene Maquiavelo, quien separa la ética de la política y recomienda incluso la inmoralidad en el ámbito de la política para la consecución de los fines. Bien es verdad que en su obra sobre el príncipe toma en consideración, sobre todo, su posición y su relación para con sus súbditos, pero estas son paradigmáticas para todo el Estado. La cuestión de si es mejor para el príncipe ser amado o temido, si solo hubiera una posibilidad, queda respondida a favor del temor:

to, manifestar - como dijimos (a.2 ad 3) - es acto de la verdad dirigido a otro en cuanto que un hombre es a otro a quien expone lo que lleva en sí. La segun$\mathrm{da}$, en cuanto que la justicia establece cierta igualdad entre las cosas, que es lo mismo que hace la verdad al establecer una ecuación entre los signos y la realidad de lo que hay en su interior».

${ }^{30}$ Nissing, 2006, pp. 471-477.

${ }^{31}$ Tomás de Aquino, Tratado del gobierno de los príncipes, p. 43. Versión latina en Tomás de Aquino, De regimine principum, p. 57 ("Quia igitur vitae, qua in praesenti bene vivimus, finis est beatitudo caelestis, ad regis officium pertinet ea ratione vitam multitudinis bonam procurare secundum quod congruit ad caelestem beatitudinem consequendam, ut scilicet ea praecipiat quae ad caelestem beatitudinem ducunt $[\ldots] »)$. 
Los hombres temen menos el ofender al que se hace amar que al que se hace temer, porque el amor no se retiene por el solo vínculo de la gratitud, que en atención a la perversidad humana, toda ocasión de interés personal llega a romper; en vez de que el temor del príncipe se mantiene siempre con el del castigo, que no abandona nunca a los hombres ${ }^{32}$.

Por supuesto, el temor no debe tornarse en odio. Así, los fines de los príncipes no son los de sus súbditos. Ello se demuestra también con claridad en la cuestión de si los príncipes deben cumplir su palabra. Con la astucia propia del zorro, los príncipes pueden alcanzar grandes cotas por medio de la infidelidad, el fingimiento, las artimañas y la falsedad. Maquiavelo presenta como modelo a seguir a Alejandro VI, quien no hizo otra cosa que no fuera engañar y siempre encontró a quien se dejara engañar.

El mundo es malo y por ese motivo, según Maquiavelo, al gobernante también le está permitido serlo:

Cuando un príncipe dotado de prudencia ve que su fidelidad en las promesas se convierte en perjuicio suyo y que las ocasiones que le determinaron a hacerlas no existen ya, no puede y aun no debe guardarlas, a no ser que él consienta en perderse.

Obsérvese bien que si todos los hombres fueran buenos este precepto sería malísimo; pero como ellos son malos y que no observarían su fe con respecto a ti si se presentara la ocasión de ello, no estás obligado ya a guardarles la tuya, cuando te es como forzado a ello ${ }^{33}$.

El gobernante ha de parecer piadoso, leal, humano, religioso y sincero, pero no ha de serlo necesariamente. No se necesita más que la apariencia de la virtud. Un príncipe novel no puede permitirse ser realmente virtuoso, "supuesto que a menudo, para conservar el orden en un Estado, está en la precisión de obrar contra su fe, contra las virtudes de humanidad, caridad, y aun contra su religión ${ }^{34}$.

Por tanto, el fin último y el programa político del príncipe es, para Maquiavelo, el afianzamiento de su posición como príncipe. Lo importante para él es la conservación de la autoridad estatal y su incremen-

${ }^{32}$ Maquiavelo, 2004, cap. XVII.

${ }^{33}$ Maquiavelo, 2004, cap. XVIII.

${ }^{34}$ Maquiavelo, 2004, cap. XVIII. 
to. Dado que en toda monarquía la autoridad estatal recae en el príncipe, la razón de Estado sirve de conocimiento de los medios necesarios para el establecimiento, mantenimiento y ampliación de este poder, tanto para él como para el conjunto del Estado. Así pues, no son ni la felicidad ni el placer, ni siquiera la celestial bienaventuranza, lo que Maquiavelo proclama como fin último común. Los fines y los modos de actuar de los príncipes son secretos y para el vulgo han de permanecer velados. La relación armoniosa de todos con todos presentada todavía en Aristóteles queda desplazada por una clara discordia. Las consecuencias de este modelo para las relaciones sociales se presentarán a continuación, donde se muestran las ideas de algunos teóricos de las relaciones sociales y de la conversación, y su relación con los modelos ya presentados de Aristóteles, santo Tomás y Maquiavelo. Por el contrario, el modelo propio del primer cristianismo, referente al rechazo de la conversación, demuestra ser en su mayor parte inapropiado como fundamento para la teoría de las relaciones sociales.

Como es sabido, Baltasar Gracián introdujo en su Discreto una serie de reglas prácticas que contribuyen al éxito de una conversación ${ }^{35}$. Además, se distanció en diversas ocasiones de Maquiavelo, aunque algunas de sus afirmaciones pueden equipararse a los puntos de partida del italiano. Si bien critica a Maquiavelo calificándolo de "falso político" ${ }^{36}$, no es menos cierto que también elogia la astucia de Odiseo, las artimañas de la zorra, recomienda astucia, artificio y la segunda intención $^{37}$ y denomina a la diplomacia "gala de la razón de Estado»" ${ }^{38}$. El político en el poder ha de saber diferenciar entre sabios y necios. Mientras que los sabios llegan hasta la esencia de las cosas, los necios se quedan en la engañosa apariencia exterior ${ }^{39}$. La apariencia es, en definitiva, lo más importante: «Valer y saberlo mostrar es valer dos vezes: lo que no se ve es como si no fuesse. [...] Prevalece el engaño y júzganse las cosas por fuera $\aleph^{+0}$. De ello deriva la importancia de la agudeza y del arte de descifrar. Ante este trasfondo, la cortesía se convierte en simple apariencia: "Ya no [...] se vive de cortesías, que es un cor-

\footnotetext{
35 Strosetzki, 2004, pp. 311-326.

${ }^{36}$ Gracián, El Criticón, p. 583.

${ }^{37}$ Jansen, 1958, p. 126.

${ }^{38}$ Gracián, Oráculo manual y Aite de prudencia, p. 90.

39) Schröder, 1966, p. 85.

40 Gracián, Oráculo marual y' Arte de prudencia, p. 89.
} 
tés engaño»" . En El Criticón se afirma: «Sabed que el peligroso mar es la corte, con la Scila de sus engaños y la Caribdis de sus mentiras ${ }^{42}$. El recelo continuo es lo único que puede ser de ayuda frente a ello: "Usase mucho el engaño: multiplíquese el recelo» ${ }^{43}$. El artificio, el engaño y el silencio esconden las verdaderas opiniones e intenciones: «El no declararse luego suspende, $[\ldots]$ amaga misterio en todo y con su misma arcanidad provoca veneración. [...] Es el recatado silencio sagrado de la cordura. [...] Imítese, pues, el proceder divino para hacer estar a la mira y al desvelo" "4 . Al igual que Maquiavelo, también Gracián da prioridad a la apariencia en el caso de los políticos: «La mayor sabiduría, hoy encargan políticos que consiste en hacer parecer» ${ }^{45}$. Así pues, allí donde el político quiere que sus intenciones aparezcan veladas para poder imponerlas, donde la apariencia y la realidad se diferencian, donde la astucia y el engaño, el artificio y el peligro determinan la forma de actuar, allí es donde nos encontramos en el universo de Maquiavelo, un universo en el que reina la discordia.

A continuación presentaremos al humanista español Juan Luis Vives con su concepción de las relaciones sociales, concepción que se apoya en la de santo Tomás, si bien se distancia de los escritos sobre la lógica de este.Vives define la lengua como herramienta, tanto del bien como del pecado. Según él, fue creada por Dios, posibilita la comunicación de las almas ocultas bajo envolturas corporales y es requisito de la sociedad humana. El saber valorar con corrección al propio yo y la propia situación ante un acto de habla es, en la misma medida, una regla de la retórica y de la ética; de hecho, para Vives el conocimiento de uno mismo es el paso previo al conocimiento de Dios. El trato con los demás ha de ser virtuoso, esto es, ha de estar determinado por la benevolencia, la modestia y el pudor. No importa que se trate con conocidos o desconocidos, con superiores en una escala jerárquica o con iguales, a todos se ha de tratar con el precepto del amor al prójimo. Así pues, la piedad y el amor al prójimo prohíben escoger la burla hacia otro como pretexto para la risa ${ }^{46}$. Vives ve jus-

${ }^{41}$ Gracián, Oráculo manual y Arte de prudencia, p. 117.

42 Gracián, El Criticón, p. 632.

${ }^{43}$ Gracián, Oráculo manual y Arte de prudencia, p. 29.

${ }^{44}$ Gracián, Oráculo manual y Arte de prudencia, p. 2.

${ }^{45}$ Gracián, El Discreto, p. 238.

${ }^{46}$ Vives, Introductio ad sapientiam, pp. 35, 37, 39. 
tificadas las relaciones jerárquicas tanto en lo teológico como en lo político: «hoc enim vult Deus propter publicam quietem $»^{47}$. Las reglas que Vives dispone para cada tipo de interlocutor están motivadas por la religión y la ética. El discurso ha de dar testimonio de la virtuosidad del orador, lo que en el caso de una mujer resulta especialmente complicado: si habla poco, parece inculta; si habla mucho, frívola; la ignorancia se interpreta como indiferencia; el conocimiento, como maldad; la respuesta titubeante, como arrogancia; la respuesta inmediata, como irreflexión ${ }^{48}$. Uno recuerda a san Ambrosio y a san Juan Crisóstomo cuando Vives, invocando a Cristo, advierte de los peligros de hablar demasiado y de la charlatanería:

Christus Dominus noster, sciens ex loquacitate plurima oriri mala, et illa in primis, quae pugnant cum capite legis suae, rixas, discordias, simultates: Ad circumspectionem loquendi interminatus est: De omni verbo otioso, quod homines fuerint locuti, reddituros eos rationem in disquisitione illa mundi ${ }^{49}$.

En el análisis de la mentira, Vives se basa en el capítulo «De mendacio" de la obra De civitate Dei de san Agustín, donde se define al mentiroso como aquel que tiene en mente algo diferente a lo que expresa en palabras y se atribuyen diferentes grados de pecado a ocho tipos de mentiras ${ }^{50}$. Vives ve clara la dimensión política y religiosa de la mentira, la cual es capaz de corromper a toda una sociedad, pues «ut quod illam [humana conditio] procul a Deo separat, diabolo similem, ac mancipium facit $\rangle^{51}$. De este modo reprende Vives la falsedad de aquellos que no cumplen sus promesas, al igual que la mentira del adulador. Uno no debe desviarse por medio de ruegos, recompensas o amenazas del precepto cristiano del amor a la verdad.

En Vives, como en santo Tomás, se muestra la correspondencia entre las reglas de la conversación, de la política y de la ética, las cuales están todas fundamentadas teológicamente.Vives define como una re-

${ }^{47}$ Vives, Introductio ad sapientiam, p. 35.

${ }^{48}$ Vives, De christiana femina, p. 129.

${ }^{49}$ Vives, Introductio ad sapientiam, p. 38.

${ }^{50}$ Agustín de Hipona, De mendacio, pp. 242, 244. Ver además: Agustín de Hipona, De doctrina christiana, pp. 462, 484, 486.

${ }^{51}$ Vives, Introductio ad sapientiam, p. 39. 
copilación de reglas en un determinado ámbito toda ciencia (ars) que está orientada a acciones ${ }^{52}$. Así, la Historia enseña reglas para el comportamiento en la vida privada, y la política, para el comportamiento en la vida pública. Vives atribuye al acto de habla un carácter universal: "quod nulla omnino vitae ratio, atque actio, carere potest sermone, publica, privata, domi, foris, cum amico, cum inimico, cum hoste, cum majore, cum minore, cum pari ${ }^{53}$. Tan universal como el acto de habla es su base moral y religiosa: «Stet tamquam in acie facundia omnis pro bono et pio contra flagitium et nefas 1$\rangle^{54}$.

Así pues, tras observar que Vives se apoya claramente en santo Tomás y que Gracián muestra cierta afinidad con Maquiavelo, pasaremos a presentar a continuación a Lucas Gracián Dantisco, quien se orienta al principio del placer y felicidad aristotélico. Su obra Galateo español, aparecida en 1590, es una traducción, enriquecida con sus propias experiencias, del Galateo italiano de Della Casa. El fin que pretenden alcanzar sus reglas es una "conversacion apazible y agradable"». Por esa razón, la regla principal es evitar todo lo desagradable. Por ello, hay que omitir "cada acto que es de enojo, o enfado a qualquier de los sentidos ${ }^{56}$. Para que a nadie le resulte demasiado complicado entender a los demás, hay que hablar todo lo claro que sea posible, «de suerte que qualquiera de la conversacion las entienda facilmente ${ }^{57}$. Hay que evitar molestar a los demás con discursos demasiado largos. Es desagradable dar consejos a los demás, pues esto podría dar la impresión de que uno quiere parecer más inteligente que el resto.

En lo que se refiere a la elección de las materias, hay que dar prioridad a lo agradable. Una materia «no debe ser fría, de poca substancia, ni baja ni vil, porque los que la oyen, en lugar de recrearse escarnecen de la plática, y del que dize también ${ }^{58}$. Si, por ejemplo, uno centra la conversación en sí mismo o en sus méritos y privile-

\footnotetext{
${ }^{52}$ Vives, De tradendis disciplinis, pp. 252-253 ("Collectio universalium praeceptorum parata ad cognoscendum, agendum, vel operandum, in certa aliqua finis latitudine [...] Artificis finis, praeceptorum est action).

${ }^{53}$ Vives, De tradendis disciplinis, p. 357.

${ }^{5+}$ Vives, De tradendis disciplinis, pp. 359-360.

${ }^{55}$ Gracián Dantisco, Galateo español, p. 10.

${ }^{56}$ Gracián Dantisco, Galateo español, p. 15.

57 Gracián Dantisco, Galateo español, pp. 133, 145, 151.

${ }^{58}$ Gracián Dantisco, Galateo español, p. 54.
} 
gios, ofenderá al oyente de modo desagradable. Gracián Dantisco no mide las mentiras con un patrón moral, sino que su criterio es el principio del placer. Puesto que las ceremonias pueden compararse a mentiras y sueños, las mentiras pueden justificarse con la ceremonia: "nosotros honramos con la vista y apariencia a aquellos que con el coraçon no les hariamos actamiento, y con todo eso la usamos por no salir de la costumbre" ${ }^{59}$. Puesto que hay tres tipos de ceremonia, "por utilidad, por vanidad, por obligacion ${ }^{(0)}$, las mentiras pueden justificarse por las exigencias de la ceremonia mediante la clasificación de cada mentira en uno u otro tipo de ceremonia. En Gracián Dantisco no aparecen en primer plano ni la necesidad de imponer frente a los demás los fines propios mediante el encubrimiento, como ocurría con Maquiavelo y Gracián, ni la necesidad de colocar la conversación al servicio de la moral y la religión, sino las conveniencias que evitan lo molesto y que persiguen, en el sentido aristotélico, la felicidad y el placer.

La tesis planteada al comienzo sobre la correspondencia entre teoría de la conversación, ética y política se ha cumplido en Aristóteles y en Gracián Dantisco. En su caso, surge una consonancia armónica derivada del hecho de que teoría de la conversación, ética y política están orientadas al mismo fin. La eutrapelia, esto es, la destreza en la conversación, ha de regirse, como las otras virtudes, por un término medio. La virtud, la amistad, la actividad y la comunidad armonizan unas con otras. Por el contrario, en el caso de san Ambrosio y de san Juan Crisóstomo se pierde la armonía, pues ética y política sirven a un fin transcendental que relativiza y cuestiona la importancia de la conversación y de sus reglas. En Vives encontramos resonancias de esta postura, pero este, como santo Tomás, emprende el intento de conciliar posturas aristotélicas y cristianas. Esto lo consigue derivando de la Teología reglas de la conversación y de la política, reglas que de este modo no devalúa sino que revaloriza. Así, para Vives la conversación está guiada por el amor al prójimo cristiano y debe dar testimonio del virtuosismo del orador. El amor a la verdad es para él un precepto cristiano y la mentira ya no es solo un pecado más o menos grave, sino también una amenaza para toda la sociedad. La consonancia en-

59 Gracián Dantisco, Galateo espaĩol, p. 83.

(1) Gracián Dantisco, Galateo espaĩol, p. 85. 
tre teoría de la conversación, ética y política queda así rehabilitada con Vives.

Con Maquiavelo se pierde de forma definitiva dicha consonancia, de la que Gracián adopta algunas ideas. En la sociedad se abre una brecha ante el príncipe que es temido, que oculta sus intenciones, que miente y engaña, pero que ha de mantener una apariencia de decoro. Su política de conservación del poder se contrapone a la ética o, por decirlo de otro modo, no le presta atención alguna. La argucia, el artificio, el engaño y el silencio se convierten aquí en las principales reglas de conversación que Gracián recomienda no solo a los poderosos, sino también a aquellos que tratan con ellos. Una conversación marcada de esta forma, derivada de la política de la conservación del poder y que desatiende la ética, crea polos opuestos. Hace del príncipe un adversario del pueblo y le convierte en paradigma de una vida en común conflictiva que adquiere su justificación solo por el axioma de la maldad de los hombres, de la que Maquiavelo está convencido. Con ello, se sitúa en oposición a Aristóteles o santo Tomás de Aquino, cuyos axiomas fundamentales eran la amistad y la eutrapelia.

\section{BIBLIOGRAFÍA}

Agustín de Hipona, De doctrina christiana, en Euvres de saint Augustin. Ir série: Opuscules, vol. 11, ed. G. Combès y M. Farges, Paris, Desclée, 1949.

- De mendacio, en Euvres de saint Augustin. Ir série: Opuscules, vol. 2, ed. G. Combès y M. Farges, Paris, Desclée, 1948.

Ambrosio de MiLÁn, De officiis ministrorum, ed. J. E. Niederhuber, Kempten, Kösel, 1917.

Aristóteles, Ética nicomáquea, Madrid, Gredos, 1985.

ColombÁs OSB, G. M., San Benito. Su vida y' su regla, edición bilingüe, Madrid, Biblioteca de Autores Cristianos, 1954.

Gracián, B., El Criticón, en Obras completas, ed. A. de Hoyo, Madrid, Aguilar, 1960.

- El Discreto, edición facsímil Huesca 1646 con una introducción de A. Egido, Zaragoza, Institución «Fernando el Católico», 2001.

- Oráculo manual y' Arte de prudencia, edición facsímil Huesca 1647 con una introducción de A. Egido, Zaragoza, Institución «Fernando el Católico», 2001.

Gracián Dantisco, L., Galateo español, Valencia, Mey, 1601.

Jansen, H., Die Grundbegriffe des Baltasar Gracián, Genf / Paris, Droz / Minard, 1958. 
Juan Crisóstomo, Homiliae in Matthaeum, en Patrologiae cursus completus, 57, ed. J.-P. Migne, Paris, Migne, 1862.

- Homilías sobre el Evangelio de San Mateo, 2 vols., Madrid, Biblioteca de Autores Cristianos, 1955.

Maquiavelo, N., El príncipe; Alicante, Biblioteca Virtual Miguel de Cervantes, 2004. (Edición digital basada en la de Buenos Aires, Espasa-Calpe, 1939, Colección Austral.)

Nissing, H.-G., Sprache als Akt bei Thomas von Aquin, Leiden / Boston, Brill, 2006.

Rahner, H., "Eutrapelie, eine vergessene Tugend», Geist und Leben, 27, 1954, pp. 346-353.

SChrö̈ner, G., Baltasar Graciáns "Criticón». Eine Untersuchung zur Beziehung zwischen Manierismus und Moralistik, München, Fink, 1966.

Strosetzki, C., "Gracián y la teoría francesa de la conversación", en Baltasar Gracián IV centenario (1601-2001), ed. A. Egido, F. Gil Encabo y J. E. Laplana, Zaragoza, Institución "Fernando el Católico», 2004, pp. 311-326.

Tomás de Aquino, De regimine principum, trad. F. Schreyvogl, Stuttgart, Reclam, 1971.

- Ethicorum Aristotelis ad Nicomachum, ed. R. Spiazzi, Rom, Marietti, 1949.

- Suma de Teología, vol. 4, Madrid, Biblioteca de Autores Cristianos, 1990.

- Summa theologica, vol. 20, "Tugenden des Gemeinschaftslebens», München / Heidelberg, Kerle, 1943.

- Summa theologica, vol. 22, "Maßhaltung 2. Teil", übers. und komm. von Dominikanern und Benediktinern Deutschlands und Österreichs, Graz / Wien / Köln, Styria, 1993.

- Tratado del gobierno de los príncipes del angélico doctor Santo Thomás de Aquino. Traducido en muestra lengua castellana por Don Alonso Ordoñez das Seyjas y Tobar, Madrid, Imprenta de Benito Cano, 1786.

Vives, J. L., De christiana femina, en Opera omnia, vol. 4, ed. G. Majansius, Valentia, Monfort, 1782-90.

- De tradendis disciplinis, en Opera omnia, vol. 6, ed. G. Majansius, Valentia, Monfort, 1782-90.

- Introductio ad sapientiam, en Opera omnia, vol. 1, ed. G. Majansius, Valentia, Monfort, 1782-90. 